\title{
Assimilation of sulphur-bearing black shale and its effects on the formation of magmatic Cu-Ni deposits - the essential role of devolatilization fluids
}

\author{
V. J. Virtanen ${ }^{*}$ and J. S. Heinonen \\ Department of Geosciences and Geography, University of Helsinki, Helsinki, Finland \\ *Corresponding author e-mail: ville.z.virtanen@helsinki.fi
}

We have conducted heating experiments, Raman spectroscopy, and thermodynamic modelling on black shale wallrock related to the $1.1 \mathrm{Ga}$ Duluth Complex, United States, to examine how contact metamorphism and partial melting mobilize $\mathrm{S}$ and $\mathrm{Cu}$ in black shales and affect $\mathrm{Cu}-\mathrm{Ni}$ deposit formation in layered intrusions. Our results show that $\mathrm{S}$ and $\mathrm{Cu}$ are effectively mobilized via devolatilization fluids, which we suggest as the main medium for $\mathrm{S}$ and $\mathrm{Cu}$ transport from black shale to magma. In addition, assimilation of black shale partial melt lowers magmas capacity to dissolve $\mathrm{S}$, which further increases the degree of sulphide saturation.

\section{Introduction and background to current research}

Assimilation of crustal wallrocks effectively modifies the thermal state and compositional identity of the interacting mantle-derived magmas. As a consequence, anomalous rock formations, such as economically important ore deposits, may arise. Assimilation has been identified as the decisive process that lead to formation of many magmatic base (and noble) metal sulphide deposits hosted by layered intrusions and komatiitic lava flows. A few notable examples include the Ni-Cu(-PGE) deposits of the Duluth Complex in the USA, Noril'sk in Russia, Kambalda in Australia, as well as Kevitsa and Sakatti in Finland (e.g., Naldrett, 1999, Maier and Hanski, 2017).

In nature, assimilation rarely is a simple mixing of two compositionally fixed chemical entities (magma and wallrock), but a complex process, where the composition of the assimilated material is governed by the thermal state and the continuously evolving wallrock phase equilibrium. In order to pinpoint the possible trigger mechanisms for the sulphide deposit formation, it is essential to understand how the wallrock reacts upon contact metamorphism and partial melting.

Partial melting processes at the contact zones of layered intrusions (PALIN) is an Academy of Finland funded research project aiming to shed knowledge on the wallrock-magma interactions. The project is involved in co-developing and utilizing the freely available Magma Chamber Simulator (MCS; Bohrson et al., 2014; https://mcs.geol.ucsb.edu/) - a thermodynamically constrained geochemical modelling software - to unravel the fundamental phenomena occurring in open magmatic systems. The unique feature in the MCS is that it can track the simultaneous phase equilibria within magma, wallrock, recharge magma batches, and stoped wallrock blocks. In the presented subproject managed by the first author, contact metamorphic and partial melting processes in natural black shale wallrock samples are studied and MCS is used to test how selective wallrock assimilation affects sulphide saturation in magmas. The project started in 2016 and ends in August 2021.

\section{Research questions at hand}

The case study for our research is the $1.1 \mathrm{Ga}$ Duluth Complex, Minnesota, where mafic magmas assimilated sulphur-bearing black shales of the adjacent $1.9 \mathrm{Ga}$ Virginia Formation. 
The assimilation triggered the genesis of one of the largest known $\mathrm{Cu}-\mathrm{Ni}(-\mathrm{PGE})$ deposit clusters in the world (e.g., Miller et al., 2002). Utilizing heating experiments and Raman spectroscopy, we aim to identify the key contact metamorphic and partial melting processes mobilizing $\mathrm{S}$ and $\mathrm{Cu}$ in the black shale wallrock. In addition, we use thermodynamic modelling to test how selective black shale assimilation affects sulphide saturation in the Duluth magmas.

\subsection{Black shale heating experiments}

Both xenoliths and the devolatilized and partially molten footwall of the Virginia Formation black shale have been suggested as the main source of $\mathrm{S}$ in the Duluth Complex Cu-Ni(-PGE) deposits. We study the relative importance of fluids and melts as the transport medium for $\mathrm{S}$ and $\mathrm{Cu}$ during assimilation.

We conducted a series of heating experiments $\left(2 \mathrm{kbar}, 700-1000^{\circ} \mathrm{C}\right)$ on a natural black shale sample from the Virginia Formation (Fig. 1a) at the experimental petrology laboratory at ETH, Zürich. These experiments showed that a carbon-oxygen-hydrogen-sulphur (COHS) fluid mobilizes $\sim 45 \%$ of the $\mathrm{S}$ and $\sim 60 \%$ of the $\mathrm{Cu}$ in the black shale already upon subsolidus devolatilization (Fig. $1 \mathrm{~b}$ and $\mathrm{d}$ ), which provides a mechanism for effective $\mathrm{S}$ and $\mathrm{Cu}$ transport to the magma. Further $\mathrm{S}$ and $\mathrm{Cu}$ assimilation can occur at $1000^{\circ} \mathrm{C}$, when the silicate partial melt becomes the volumetrically dominant phase. At the same temperature, monosulphide solid solution and $\mathrm{Cu}$-rich sulphide melt attach to the devolatilization fluid bubbles (Fig. 1c and e) promoting buoyant transportation to the magma.

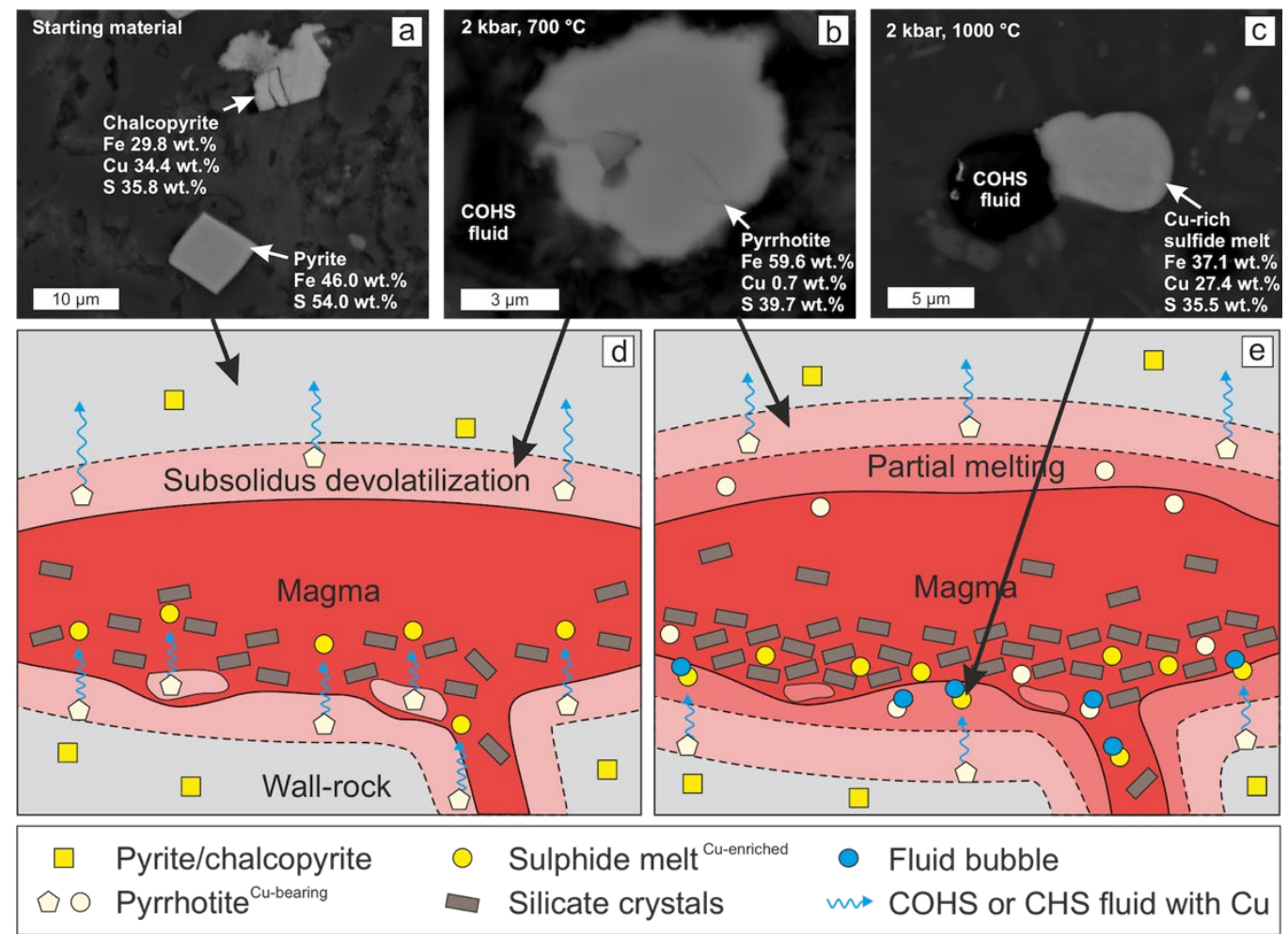

Figure 8. Back-scattered electron images of sulphide phases present in a. natural pristine black shale starting material (thin section) as well as in the experiments at b. $700^{\circ} \mathrm{C}$ and c. $1000{ }^{\circ} \mathrm{C}$. The compositions were measured semiquantitatively with energy dispersive detector of field emission scanning electron microscope. Cu-bearing monosulphide solid solution is the main sulphide phase at $1000{ }^{\circ} \mathrm{C}$ (not shown). The schematic model for black shale assimilation shows how $\mathrm{S}$ and $\mathrm{Cu}$ could be transported to the magma at $\mathrm{d}$. subsolidus devolatilization conditions and e. during partial melting. 


\subsection{Raman spectroscopy of organic carbon speciation in the contact aureole}

Kerogen (a hydrocarbon compound) observed in pristine Virginia Formation samples has transformed into graphite at the proximity of the Duluth Complex (Fig. 2). Graphitization of kerogen is associated with release of hydrocarbons, which potentially mobilize sulphur as $\mathrm{H}_{2} \mathrm{~S}$ by reducing pyrite to pyrrhotite at early stage of contact metamorphism (Fig. 2).

Raman spectroscopy can be used to determine the structure of the organic carbon species. We aim to characterize the graphitization process with a set of natural samples from outside and inside the Virginia Formation contact aureole (Fig. 2) and determine if a hydrocarbon-bearing fluid could have mobilized $\mathrm{S}$ or not. We expect this study to provide insight into the role of fluids in the assimilation of $\mathrm{S}$ and $\mathrm{Cu}$.
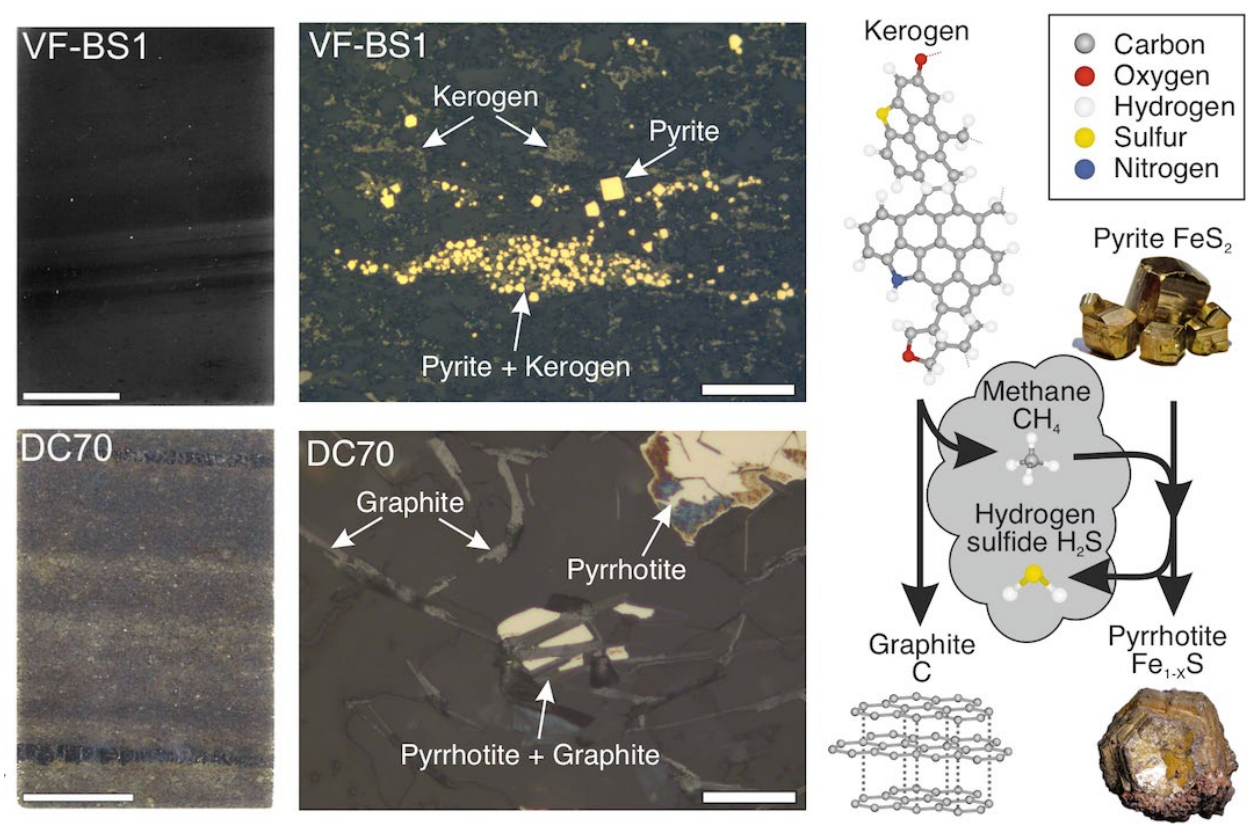

Figure 9. On the left, thin sections of pristine (VF-BS1) and contact metamorphosed (DC70) black shale from the Virginia Formation. In the middle, reflected light photomicrographs of the same samples showing the main organic carbon and sulphide species. On the right, a schematic model of the proposed contact metamorphic reaction where graphitization of kerogen releases methane, which reduces pyrite to pyrrhotite, while releasing hydrogen sulphide.

\subsection{Magma Chamber Simulator modelling}

Assimilation of sulphur-bearing wallrock is known to increase the degree of sulphide saturation in magma, but the lack of thermodynamic modelling tools for open magmatic systems has hampered the detailed description of the process. The effect of continuous assimilation of wallrock partial melt to the S budget and SCSS in the magma has not been tested before.

We used the MCS to examine how assimilation of the Virginia Formation black shale affected the formation of the magmatic Cu-Ni deposits of the Duluth Complex. We tentatively modelled $\mathrm{S}$ as a trace element to give insight into its mobility during black shale partial melting. The models show how the assimilation of thermodynamically constrained wallrock partial melt changes the major element composition of the magma promoting sulphide saturation (Fig. 3). The trace element models, where restite ${ }^{\text {wallrock} / \text { partial melt }}{ }^{\text {wallrock }}$ partition coefficient for S are $\leq 1$ (Fig. 3), are compatible with the pre-existing S isotopic data (Ripley 1981) and with our heating experiments, where subsolidus devolatilization effectively mobilizes $\mathrm{S}$. 

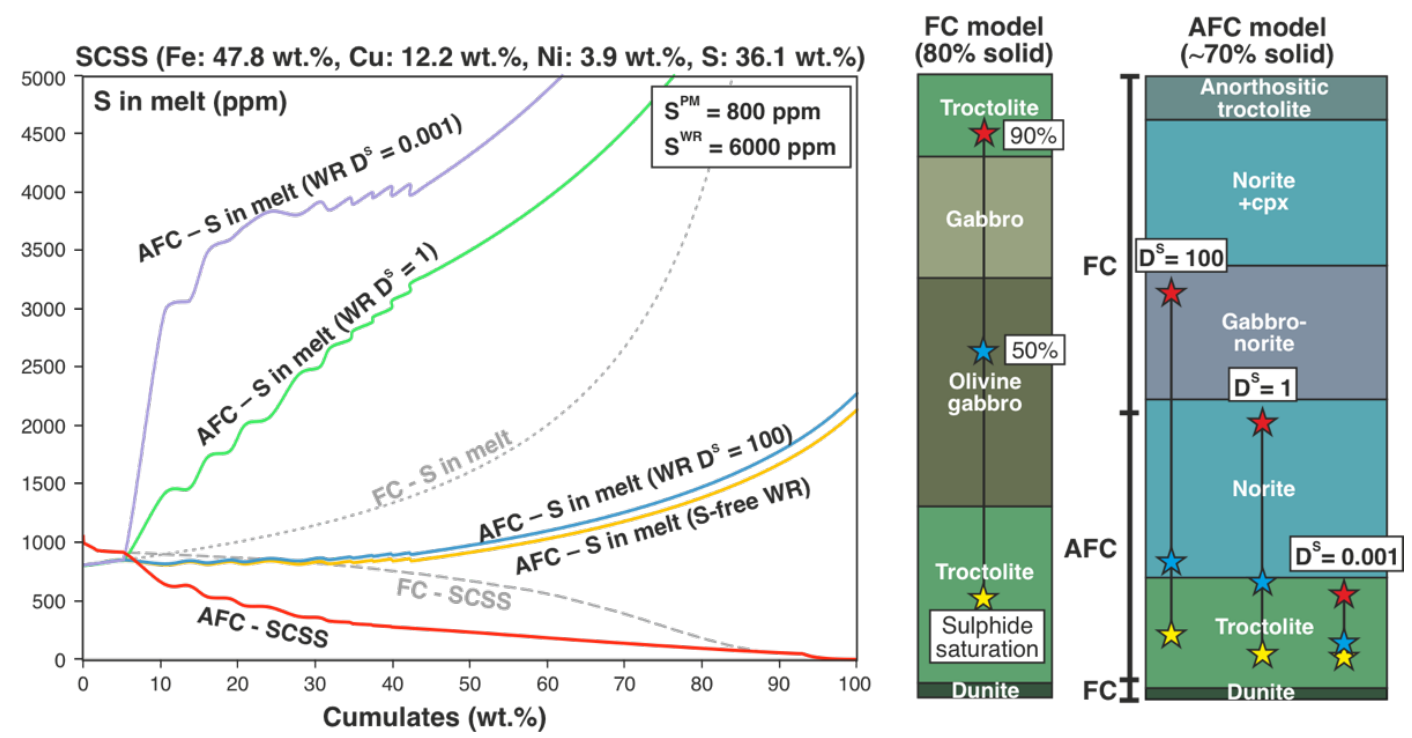

Figure 10. The sulphur content at sulphide saturation (SCSS) and S contents for fractional crystallization (FC) and assimilation-fractional crystallization (AFC) models conducted with the Magma Chamber Simulator. The initial S content of the parental melt is $800 \mathrm{ppm}$ and of the wallrock $6000 \mathrm{ppm}$. The $\mathrm{D}^{\mathrm{S}}$ indicates restite ${ }^{\text {wallrock}} /$ partial melt ${ }^{\text {wallrock }}$ partition coefficients for $\mathrm{S}$ in the AFC models. SCSS is calculated according to Smythe et al. (2017). The modelled cumulate stratigraphies for the same models. The stars indicate sulphide saturation (yellow) as well as 50\% (blue) and $90 \%$ (red) sulphide precipitation (of total precipitated according to the model).

\section{Future prospects}

We intend to utilize the aforementioned methodology to other sulphide-rich magmatic systems that were susceptible to wallrock assimilation. Especially attractive prospects are the $\mathrm{Ni}-\mathrm{Cu}(-$ PGE) deposit-hosting layered intrusions in Fennoscandia, such as Kevitsa and Sakatti, of which many show signs of wallrock assimilation (Maier and Hanski, 2017).

\section{Acknowledgements}

Ferenc Molnár, Max Schmidt, Felix Marxer, Pietari Skyttä, Karina Moslova, Nicholas Barber, Matthieu Galvez, and Lena Märki are thanked for their invaluable interpretational and analytical contributions. The staff of the Hibbing Drill Core Library of the Minnesota Department of Natural Resources, Lands, and Minerals Division, Edward Sawyer, and SarahJane Barnes kindly provided us with the necessary samples. The mineral photographs in the figure 2 were taken by Milla Aaltonen (pyrite) and Aku Heinonen (pyrrhotite). The PALIN project is funded by the Academy of Finland Grants 295129, 306962, and 327358.

\section{References:}

Bohrson WA, Spera FJ, Ghiorso MS, Brown G.A, Creamer JB, Mayfield A (2014) Thermodynamic model for energy-constrained open-system evolution of crustal magma bodies undergoing simultaneous recharge, assimilation and crystallization: the Magma Chamber Simulator. J Petrol 55:1685-1717.

Maier WD, Hanski EJ (2017) Layered Mafic-Ultramafic Intrusions of Fennoscandia: Europe's Treasure Chest of Magmatic Metal Deposits. Elements 13:415-420.

Miller JD Jr, Green JC, Severson MJ, Chandler VW, Hauck SA, Peterson DM, Wahl TE (2002) Geology and mineral potential of the Duluth Complex and related rocks of Northeastern Minnesota. Minn Geol Surv ROI 58, pp. 207.

Naldrett AJ (1999) World-class Ni-Cu-PGE deposits: key factors in their genesis. Miner Depos 34:227-240.

Ripley EM (1981) Sulfur Isotopic Studies of the Dunka Road Cu-Ni Deposit, Duluth Complex, Minnesota. Econ Geol 76:610-620.

Smythe DJ, Wood BJ, Kiseeva ES (2017) The S content of silicate melts at sulfide saturation: New experiments and a model incorporating the effects of sulfide composition. Amer Miner 102:795-803. 